\title{
Crutches No More: Reframing Philip Johnson's Seven Crutches as Pedagogic Tools
}

\author{
KYLE SCHUMANN
}

Princeton University

\begin{abstract}
With the discipline of architecture expanding into other fields and the ethical positions of the profession being redefined, a look to past lessons, in retrospect, can equip us with tools to address these concerns. Philip Johnson's "The Seven Crutches of Modern Architecture" provides such a perspective once the ideas are reframed as pedagogic tools.
\end{abstract}

\section{INTRODUCTION}

In December 1954, Philip Johnson gave a talk to a group of architecture students at Harvard University's Graduate School of Design. This talk, "The Seven Crutches of Modern Architecture," published a year later in Yale's Perspecta 3, details Johnson's seven warnings to architectural professionals and students alike. Johnson's attitude from the outset is bombastic, and he immediately undermines his own talk by claiming that architecture cannot be taught and should not be talked about but should be simply produced. Johnson's message was nonetheless given within the context of the academy, both in a talk to students and in an academic journal, and we should therefore look past his efforts to put on airs as an aloof, enigmatic master and consider his discussion within a pedagogic framework.

In the order presented, the crutches are: The Crutch of History, the Crutch of Pretty Drawing, the Crutch of Utility, the Crutch of Comfort, the Crutch of Cheapness, the Crutch of Serving the Client, and the Crutch of Structure. ${ }^{1}$ Decades later, in Princeton's Pidgin Magazine 10, Sylvia Lavin proposed an eighth, the Crutch of Program. ${ }^{2}$

The crutches are presented in 1954 as warnings and as linguistic excuses to justify hollow or otherwise questionable design decisions. Johnson praises those "strong enough not to bother with the crutches" in making "the sum of inescapable artistic decisions that [one has] to make." In arguing that one must "face the fact that to create something is a direct experience," 3 Johnson directly addresses questions at the core of architectural design - the daily making of design decisions at every scale. He casts the crutches in an inimical light, painting a picture of the architect as a master artist, answering to no one outside of his or her own sensibility and methodology. This attitude of authority raises several ethical questions, and speaks to Johnson's background as a privileged white male in the center of the institutionalized art world at the Museum of Modern Art.
Johnson's candid simplification of the crutches as bad habits creates bold, alluring statements in the format of an informal academic talk, but fails to address their complexity as nuanced tools for the opportunistic designer and, more importantly, as a valuable pedagogic apparatus for students of architecture. Furthermore, as the discipline of architecture suffers from a narrowing of the definition of ethics, it comes to light that each crutch addresses, in some form or another, a concern that is inherently ethical. The Crutch of History encompasses culturally sensitive issues, the Crutch of Pretty Drawing addresses professional concerns of clear communication through representation, the Crutch of Utility describes functional requirements, and the Crutch of Comfort necessitates accessibility. Meanwhile, the Crutch of Cheapness requires a responsibility to budgetary restraints, the Crutch of Serving the Client ensures a professional relationship with the architect, and the Crutch of Structure dictates building codes and life safety. Even Lavin's Crutch of Program aids in ensuring a successful project emerges for the client.

\section{CONTEMPORARY REFRAMING}

If we consider the reframing of the crutches relative to contemporary architectural practice and education in the $21^{\text {st }}$ century, we find that the discipline is facing an identity crisis as the end of the digital ushers in a yet uncertain post-digital age. The dissemination of architectural works occurs primarily through online thumbnails and slideshows-quick-fire peepshows favoring bold imagery and flashy diagrams. As the crutches are rejected, so is the specificity and sensitivity they enable in projects. I would argue for an architecture that favors thoughtfulness over sensationalism-a thoughtfulness that may very well begin with a crutch.

While Johnson and Lavin's cautionary approach to the crutches is occasionally beneficial, the crutches should not be rejected outright. Doing so relinquishes a valuable set of tools that can reveal embedded potentials in any given design problem and confront today's ethical issues in the profession head on. The crutches are useful to all architects but particularly to students, who fumble to find a way through the uncertainty of the design process, and carry early lessons and working methods with them through their careers. Early design prompts can be daunting to students who have lived their educational lives thus far under the presumption that there are facts, equations, formulae, and logic that lead to quantifiable solutions. Anyone who has been through a design studio understands well that this method of thought 
simply does not hold up. If unequipped with proper methods to address problems, students either revert to mimicry, copypasting elements found on site, or imitation of a previously experienced 'historical style.'

The crutches are the answer to this naive, baseless designing in the void. If we embrace them as pedagogic and ethical tools, we will discover the crutches to be generators for architecture that is responsive and sensitive to site, program, clients, and other formal, material, and cultural contexts, thereby addressing the fundamental challenge of acontextual sensationalism in contemporary architecture. We can analyze each of the crutches, reframing them around their pedagogic potential while heeding the warnings of Johnson and Lavin.

\section{JOHNSON'S SEVEN CRUTCHES}

The timing and context of Johnson's 1954 talk must be considered when discussing the potential value of the crutches today. Much has changed in the world and in the practice of architecture in the six intermediate decades. Johnson's derogatory use of the term 'crutch' is problematic, and when considered together with his dismissal of clients and their wishes, signals the outdated ethical climate in which Johnson began practicing architecture and in which his talk was situated. Many qualities of the crutches that Johnson so disparages are cornerstones of the architectural profession and important aspects of the licensure process. His talk predated standardized national licensure procedures, as NCARB did not administer the first national exam for architects until $1965 .^{4}$

\section{CRUTCH OF HISTORY}

Johnson dismisses the Crutch of History as irrelevant-"The most important crutch in recent times is not valid ... History doesn't bother us very much now"5 - and does not elaborate. Johnson's indifference to history can be traced to his training in modernism and the paradigm shift it engendered in the profession. Today, while designing in historical or other architectural 'styles' - of which Johnson himself is frequently guilty, as with the Miami Cultural Center-remains taboo, history often provides a meaningful reference point for architecture and placemaking. Whether learning how to properly apply local materials or looking to the vernacular for ingenious passive environmental strategies, specific histories of a site-cultural, formal, material, functional, etc. - can reveal opportunities for generating well situated contextual designs.

\section{CRUTCH OF PRETTY DRAWING}

Defining a line between drawing and building, Johnson remarks, "You can give yourself the illusion that you are creating architecture while you're making pretty drawings. ... Fundamentally, architecture is something you build and put together, and people walk in and they like it." In 1954, the Crutch of Pretty Drawing was "still with us ... [but] pretty well gone." ${ }^{6}$ Fast forward to 2018 and we observe a resurgence of the Crutch of Pretty Drawing, or as we might now rename it to include the pervasive architectural rendering, the Crutch of Representation. As line drawings take a backseat in both schools and practice to rendering, collage, illustration, and a plethora of alternative flashy imagery, a different type of pretty drawing takes hold.

Johnson's "cult of the pretty plan"7 advocated for drawing specifically as a form of architectural literacy and communication-Johnson's pretty drawings used well established conventions such as lineweight and projection to convey architectural space. The new Crutch of Representation is of a different character, straying far from the physical building of architecture into the realm of aesthetics and graphic design. The new crutch is one that fetishizes imagery, 'enhancing' drawings with arbitrary aesthetic embellishment-neon colors, gradients, flocks of birds, children with red balloons, etc. While adding visual interest to the drawing and forming a branded, signature look for the author, these moves run the risk of-and are at their most heinous when-failing to contribute to the quality of the architecture that the drawing exists to describe, thus becoming ultimately meaningless. Le Corbusier famously praised the communicative value of drawing; "I prefer drawing to talking. Drawing is faster, and leaves less room for lies." ${ }^{8}$ Lest we not forget that architects ultimately produce physical constructions and space, which requires clear and precise communication via visual media with contractors and other collaborators-the endgame cannot be willful image making.

\section{CRUTCH OF UTILITY}

Johnson goes so far as to rid architecture of its function: "They say a building is good architecture if it works. Of course, this is poppy-cock. All buildings work." ${ }^{\prime 9}$ All buildings do not work, and to naively make a blanket claim as such is a hugely problematic. To fulfill their most basic professional and ethical duties, architects must make buildings that function. To function, buildings must provide for their inhabitants in meaningful ways, at bare minimum meeting building codes and structural requirements. Take Cornell University's new architecture studio Milstein Hall, by the progressive Office for Metropolitan Architecture, for example. Shortly after opening, the maximum occupancy of Milstein's spectacular domed critique space was lowered from several hundred to forty-nine due to fire code violations, therefore eliminating the space for use in exhibition and lecture receptions and large reviews, and in the process, failing to meet its primary function.

However, Johnson wisely cautions against solely serving codes-"If the business of getting the house to run well takes precedence over your artistic invention the result won't be architecture at all; merely an assemblage of useful parts." ${ }^{10}$ Yet these useful parts are not to be overlooked, as they provide necessary functions and can also furnish inspiration and purpose for a project. It is in the thoughtful combining 
of these parts that a project transcends building and becomes architecture. Beauty without usefulness remains in the realm of sculpture, which lacks the ethical responsibilities of a licensed profession.

\section{CRUTCH OF COMFORT}

Johnson takes issue with the rise of building systems; "After all, what is architecture but for the comforts of the people that live there? But when that is made into a crutch for doing architecture, environmental control starts to replace architecture."11 Certainly no one practicing today wants architecture to be reduced to a scaffold for thermostats and HVAC systems. Reyner Banham addresses this critique of comfort in his writing on mechanical infrastructure of the home, discussing the Glass House:

“... Philip Johnson says that the place is not a controlled environment ... In fact, he is simply exploiting the campfire phenomenon (he is also pretending that the floor-heating does not make the whole area habitable, which it does) and in any case, what does he mean by a controlled environment? It is not the same thing as a uniform environment, it is simply an environment suited to what you are going to do next, and whether you build a stone monument, move away from the fire or turn on the air-conditioning, it the same basic human gesture you are making." 12

Johnson muddles the issue with a discussion on the role of aesthetics in producing perceived comfort, using chairs as his example. Furniture works well as a way of quantifying comfort, with tighter tolerances and a more overt relationship to the human body than larger architectural works. Architects would do well to heed the universal value of comfort highlighted by Banham, while approaching perceived aesthetic comfort with caution.

\section{CRUTCH OF CHEAPNESS}

Perhaps the most practical crutch, the Crutch of Cheapness is a legitimate concern for all built projects. "Anybody that can build a $\$ 25,000$ house has indeed reason to be proud, but is he talking about architecture or his economic ability?"13 Cheapness is not the sole goal of a work of architecture-that honor belongs to run-of-the-mill contractors and developers-nor should economic limitations be an effective excuse for bad architecture. However, economic efficiency is not a bad thing, and is necessary to serve large portions of the population who may not be able to afford excessive fees yet are equally deserving of a well-designed environment. Additionally, being creative with a frugal budget can often serve to clarify the most important aspects of a project and improve the richness of an architectural proposal. One might refer to Carlo Scapa's constant pairing of precious and mundane materials, such as marble and concrete, at Querini Stampalia, Castelvecchio and other projects, or to the scarce budgets of many projects by Rural Studio or Marlon
Blackwell Architects to find successful examples of cheapness not as an excuse but as a productive limitation.

\section{CRUTCH OF SERVING THE CLIENT}

Like the Crutch of Cheapness, the Crutch of Serving the Client can be a blanket excuse. "You can escape all criticism if you can say, 'Well, the client wanted it that way.' ... where do you draw the line? When do the client's demands permit you to shoot him, and when do you give in gracefully?"14 Clients can certainly make ridiculous demands that are bound to result in less than ideal architectural solutions, and it is the responsibility of an architect to work through and reconcile any curveballs thrown by the client. Furthermore, it is the architect's ethical responsibility as a licensed professional to help the client realize his or her objectives.

Architects are generalists, not specialists, and should avoid the Howard Roarkian arrogant starchitect stereotype by remembering that they may have much to learn from their clients. When designing a home in a faraway place, homeowners will teach the architect about domesticity in a foreign culture. When designing a hospital, doctors will educate the architect about new ways of treating clients. When designing a kindergarten, teachers will inform the architect about nuanced behaviors of children, insights which could only have been garnered through decades of interaction and observation. The relationship between architect and client is at its most productive when both parties are collaborators, contributing their own expertise while referring to the other's judgement in more unfamiliar matters. The Eames were known for openly admitting their lack of expertise in specialty areas, instead embracing learning and exploration to engage meaningfully with clients-a strategy which landed them many successful projects with interesting and engaged clients.

\section{CRUTCH OF STRUCTURE}

Johnson declares the Crutch of Structure to be "Perhaps the most trouble of all." He confesses to using the crutch constantly, but proceeds to criticize Buckminster Fuller for making structure and not architecture:

"Sculpture alone cannot result in architecture because architecture has problems that Bucky Fuller has not faced, like how do you get in and out. Structure is a very dangerous thing to cling to. You can be led to believe that clear structure clearly expressed will end up being architecture by itself." 15

While parts of this may be true, one cannot ignore the multitude of lauded architects who have embraced and expressed structure with sincerity and clarity-Nervi, Dieste, Kahn, Foster, etc. Moreover, adhering to building codes is one of the most fundamental ethical tasks for a licensed architect in order to ensure life safety. 
In 2018, a different facet of the crutch has emerged, heralded by the switch to digital tools. One should be cautious not to forget about structure and become so enamored with the virtual, free from gravity and the laws of physics, that one risks serious problems in translation to physical materials. BIM coordination software also presents a crutch, making it too easy for architects to select material assemblies from a catalog, resulting in a clunky agglomeration of various wall types and finishes. The tragic ending to this narrative is a winning digital competition entry that must transform to an unrecognizable state to become physical. In the least ethical version of this scenario, the built project is then presented by the architect in deceitful doctored photographs erasing unsightly but necessary structural elements.

\section{LAVIN'S EIGHTH CRUTCH}

It has only been a few years since Lavin introduced the eighth crutch, so her argument can be considered within a more contemporary context.

\section{CRUTCH OF PROGRAM}

Program, in my opinion, is nearing the end of its usefulness... An endless list of uses, spaces, and relations may make it possible for an architect to construct a building but it bears no relation to the rich mix of social, material, cultural, and affective life that makes a school. Programs are pure speculations and arguments, they have nothing, like gravity, that they can fall back on or down with. ${ }^{16}$

Program is possibly the most important and encompassing of the crutches. Program involves more than a list of required functions notated with requisite areas and a bubble diagram describing preferred adjacencies, or Lavin's "endless list of uses, spaces, and relations". The "... rich mix of social, material, cultural, and affective life" is intrinsic to program when considered within a certain site and therefore a specific social, material, cultural, and affective framework. It is these qualities of program, not the quantitative list of square footages, that contribute most significantly to the development of an architectural project. Bernard Tschumi's event architecture and combinatory programs of the National Library of France proposal is a prime example of the potential of program as a generator of architectural ideas.

Program is also closely aligned with the needs of a client, and therefore an extension of both the Crutch of Serving the Client and the Crutch of Utility. Program does not fall back on gravity, but on the client's needs and desires.

\section{LOOKING FORWARD}

It may be that experienced architects can forego reliance on the crutches and lean on their embedded ethical experience, just as a student who has mastered the literacy of architectural drawing no longer needs to struggle long hours perfecting lineweights to properly convey space. But especially for students new to architectural design, the crutches are instrumental in developing a reliable approach capable of generating specific architectural responses and teaching awareness of ethical concerns relevant to practice in the professional world.

Johnson describes the challenge of making a design decision: "... there is no one to tell you whether your one choice out of, say, six billion for the proportion of a window is going to be right. No one can go with you into that room where you make the final decision." ${ }^{17}$ Indeed, the ultimate decision often rests with the architect as author of an architectural project, but this decision can be aided by influence of any one of the crutches, or by collaborators such as engineers, consultants, and yes, even the client.

At the same time, the crutches-especially just a single crutch - should not become the sole generators of an architectural project. Students need to learn, and practitioners need to remember that design is a nuanced balance of countless pressures vying for influence over a project. To have a single crutch dominate design decisions is to forfeit authorship of the project. Students should be encouraged to lean on the crutches, understanding them not as sole drivers but as opportunistic generators. With time, direct dependence upon them wanes, but the various approaches to design decision making are remembered and ingrained in the design process of a new generation of architects.

\section{ENDNOTES}

1 Philip Johnson, "The Seven Crutches of Modern Architecture," Perspecta 3 (1955): 40-45.

2 Sylvia Lavin, "Design by Mood: Program in the Seattle Public Library," Pidgin Magazine 10 (2011): 24-33.

3 Philip Johnson, "The Seven Crutches of Modern Architecture," Perspecta 3 (1955): 44.

4 Ibid, 41

5 "History of the ARE," NCARB, National Council of Architectural Registration Boards, https://www.ncarb.org/about/history-ncarb/history-are.

6 Johnson, "The Seven Crutches of Modern Architecture," 41

7 Ibid.

8 Julia McMorrough, Drawing for Architects: How to Explore Concepts, Define Elements, and Create Effective Built Design through Illustration (Beverly, MA: Rockport Publishers, 2015), 8.

9 Philip Johnson, “The Seven Crutches of Modern Architecture," Perspecta 3 (1955): 42.

10 Ibid.

11 Ibid.

12 Reyner Banham, "A Home is Not a House," Art in America 2 (1965): 79.

13 Philip Johnson, "The Seven Crutches of Modern Architecture," Perspecta 3 (1955): 43.

14 Ibid.

15 Ibid.

16 Sylvia Lavin, "Design by Mood: Program in the Seattle Public Library," Pidgin Magazine 10 (2011): 25.

17 Philip Johnson, "The Seven Crutches of Modern Architecture," Perspecta 3 (1955): 43-44. 